\title{
Antioxidant properties of 5-ASA: Potential mechanism for its anti-inflammatory activity
}

T YAMADA, MD, C VOLKMER, BS, MB GRISHAM, PHD

\begin{abstract}
There is a growing body of experimental data to suggest that the inflamed intestine and/or colon may be subjected to considerable oxidative stress. The most probable source of these oxidants are the phagocytic leukocytes, since these cells are present in large numbers in the inflamed mucosa and are known to produce significant amounts of potentially injurious reactive oxygen species in response to inflammatory stimuli. The authors' laboratory and others have demonstrated that 5 -aminosalicylic acid (5-ASA) possesses potent antioxidant activity, including free radical scavenging properties and the ability to decompose neutrophilic oxidants (eg, hypochlorous acid) and detoxify hemoprotein-associated oxidizing agents. 5-ASA has the additional property of being able to chelate iron and render it poorly redox active. Therefore, it is proposed that much of the anti-inflammatory activity of 5-ASA may be due to its numerous antioxidant properties. Can J Gastroenterol 1990;4(7):295-302
\end{abstract}

Key Words: Etiology, Intestinal injury, Neutrophils, Oxidants

\section{Les propriétés antioxydantes de l'acide 5-aminosalicylique: Mécanisme possible de son activité anti-inflammatoire}

RESUME: Des données expérimentales de plus en plus nombreuses suggèrent que l'intestin ou le côlon irrité est peut-être assujetti à un stress oxydatif considérable. Il est probable que les oxydants responsables proviennent des leucocytes phagocytaires qui abondent dans la muqueuse enflammée: on sait en effet qu'ils produisent, en réaction aux stimuli inflammatoires, des quantités considérables d'espèces oxygénées réactives potentiellement nuisibles. Les études effectuées en laboratoire, par les auteurs et d'autres chercheurs, démontrent que l'acide 5-aminosalicylique (5-ASA) est un antioxydant puissant; il a la capacité d'éliminer les radicaux libres, de décomposer les oxydants neutrophiles (acide hypochloreux) et de détoxifier l'hémoprotéine associée aux agents oxydants. Le 5-ASA a de plus la propriété de chelater le fer et d'en affaiblir l'action oxydoréductrice. C'est pourquoi il est suggéré que l'action anti-inflammatoire du 5-ASA serait due en grande partie à ses nombreuses propriétés antioxydantes.

Department of Physiology and Biophysics, Louisiana State University Medical Center, Shreveport, Louisiana, USA

Correspondence and reprints: Dr MB Grisham, Department of Physiology and Biophysics, LSU Medical Center, 1501 Kings Highway, Shreveport, LA 71130-3932, USA $\bigcup$ LCERATIVE COLITIS IS A RECURrent inflammation of the colon and rectum characterized by rectal bleeding, diarrhea, fever, pain, anorexia and weight loss. Active episodes of this disease are characterized by the extravasation and infiltration of large numbers of inflammatory leukocytes (neutrophils, eosinophils, monocytes and macrophages) into the colonic mucosa (1). This enhanced inflammatory infiltrate is accompanied by extensive mucosal injury including edema, crypt abscesses, loss of goblet cells, decreased mucus production, erosions and mucosal ulcerations (1). Oral administration of sulphasalazine has been shown to be very effective in attenuating the mucosal inflammation and injury associated with this disease. Pharmacokinetic studies have demonstrated that sulphasalazine passes through the upper gastrointestinal tract unmodified until it reaches the colon, where it is metabolized by endogenous bacteria to yield 5-aminosalicylic acid (5-ASA) and sulfapyridine. Several clinical studies have demonstrated that 5-ASA is the pharmacologically active moiety of sulphasalazine $(2-4)$.

\section{PROPOSED MECHANISMS OF ACTION OF 5-ASA}

Although sulphasalazine has been used clinically for more than 40 years, the mechanism(s) by which 5-ASA 
TABLE 1

Proposed mechanisms of action of 5-aminosalicylic acid (5-ASA)

\begin{tabular}{|c|c|c|}
\hline & $\mathrm{I}_{50}(\mu \mathrm{M})$ & Reference \\
\hline Cyclo-oxygenase inhibitor & 10.000 & 6 \\
\hline Lipoxygenase inhibitor & 6000 & 8 \\
\hline \multicolumn{3}{|l|}{ Inhibitor of neutrophil function } \\
\hline Phagocytosis & NE & 9 \\
\hline Chemotaxis & NE & 9 \\
\hline Degranulation & NE & 9 \\
\hline FMLP binding & $>5000$ & 13 \\
\hline Inhibitor of antibody secretion & $1050-1350$ & 14 \\
\hline \multicolumn{3}{|l|}{ Antioxidant } \\
\hline Superoxide radical scavenger & $10-20$ & 18 \\
\hline Hydroxyl radical scavenger & $400-1000$ & 17.37 \\
\hline $\begin{array}{l}\text { Carbon-, peroxyl- or nitrogen-centred free } \\
\text { radical scavenger }\end{array}$ & 5-10 & 19.PS \\
\hline Hypochlorous acid scavenger & $25-400$ & 17,38 \\
\hline Iron chelator & 300 & 37 \\
\hline $\begin{array}{l}\text { Scavenger of hemoprotein-associated } \\
\text { oxidants }\end{array}$ & $20-50$ & 38.PS \\
\hline
\end{tabular}

protects the mucosa during active episodes of ulcerative colitis remains only speculative. It has been suggested that 5-ASA may exert its protective effect by inhibiting the enzyme cyclooxygenase, thus attenuating the formation of potentially pro-inflammatory prostaglandins $(5,6)$. The concentration required to inhibit this enzyme by $50 \%$ ( $\mathrm{CC}_{50}$ ) was found to be approximately $10 \mathrm{mM}(6)$ (Table 1).

The initial enthusiasm for this mechanism has diminished over the past few years after it was discovered that more potent and specific inhibitors of cyclo-oxygenase may actually exacerbate inflammatory tissue injury. Work by Stenson and colleagues $(7,8)$ has demonstrated that sulphasalazine and to a lesser extent 5 ASA are capable of inhibiting lipoxygenase activity from activated neutrophils. Using leukotriene B4 synthesis as a measure of lipoxygenase activity, they found that the IC50s for sulphasalazine and 5-ASA were approximately 0.8 and $6.0 \mathrm{mM}$, respectively, when exogenous arachidonic acid was included as the substrate. However, the $\mathrm{IC}_{50}$ s increased to 2.8 and $6.4 \mathrm{mM}$, respectively, when endogenous arachidonic acid was used as the substrate (8). The physiological significance of inhibition by the parent drug (sulphasalazine) is presently un- clear. In addition to inhibition of arachidonate metabolism, high concentrations of sulphasalazine and 5 ASA have been shown to inhibit certain functions of human neutrophils such as migration, degranulation, phagocytosis and superoxide formation (9-12). It has also been determined that high concentrations of sulphasalazine and 5-ASA inhibit the binding of the bacterial peptide, $n$-formyl-methionylleucyl-phenylalanine (FMLP) to human neutrophils, thereby inhibiting FMLP-induced arthritis in rabbits and FMLP-induced oxygen radical formation in vitro (13). A recent report by MacDermott et al (14) shows that 5 . ASA is effective at inhibiting mitogenstimulated secretion of immunoglobulins synthesized by peripheral blood and intestinal mononuclear leukocytes. The IC50 for 5-ASA in this particular study was approximately 1.0 to $1.35 \mathrm{mM}$ (14). Again, as with the studies on neutrophil function, the physiological significance of inhibition of leukocyte metabolism and function using high concentrations of sulphasalazine or 5-ASA is, at the present time, not apparent. More recent work has demonstrated that 5-ASA has potent antioxidant or free radical scavenging properties in vitro, which has been suggested to account for some of its therapeutic efficacy in vivo (15.
23). A major limitation in defining the protective mechanisms of 5-ASA has been uncertainty regarding the concentration of this anti-inflammatory agent within the colonic mucosal interstitium. The authors recently determined the colonic interstitial concentrations of 5.ASA and its $n$-acetylated derivative in the healthy feline colon perfused with concentrations of 5-ASA known to result from oral administration of sulphasalazine or from intrarectal administration of 5 . ASA preparations. It was found that perfusion of the colonic lumen with 10 mM 5-ASA produced an interstitial concentration of 5-ASA of approximately 100 to $150 \mu \mathrm{M}(24)$. This represented only 1 to $2 \%$ of the total luminal 5-ASA delivered to the mucosa. These studies also revealed that the cat has a diminished capacity to $n$-acetylate 5-ASA, since only a small percentage (less than 10\%) of the drug was detected as n-acetyl-5-ASA in the mucosal interstitium (24). The results of this study appear to have im. portant implications relative to the extrapolation of in vitro experiments regarding proposed mechanisms of action of 5-ASA and their respective IC50s (Table 1). For example, studies that implicate inhibition of arachidonate metabolism or leukocyte func. tion require concentrations of 5-ASA greater than $1000 \mu \mathrm{M}$ - a level far in excess of the mucosal interstitial con. centrations determined for the colon. These data appear to minimize the role of 5-ASA as an inhibitor of arachidonate metabolism or leukocyte function. However, it should be noted that the inflamed mucosa may be more permeable to 5-ASA than healthy colon. Interestingly, the IC50s of 5-ASA for a variety of antioxidant mechanisms fall within the experimentally determined interstitial concentrations, suggesting that some of the antioxidant properties of 5-ASA may be operative in vivo. If one of the major mechanisms of action of 5-ASA is as an antioxidant or free radical scavenger, then one would predict that the intestinal mucosa may be subjected to significant oxidative stress during active episodes of inflam. mation. The following section discusses 
evidence which supports the idea that intestinal inflammation enhances reactive oxygen metabolism.

\section{REACTIVE OXYGEN METABOLISM DURING INTESTINAL INFLAMMATION}

One of the hallmarks of active episodes of colitis is the infiltration of large numbers of phagocytic leukocytes into the mucosal interstitium. Recent evidence suggests that the infiltration of these inflammatory cells may be mediated by the potent pro-inflammatory agents leukotriene $B_{4}$ and/or platelet activating factor, since both of these mediators have been shown to be elevated in inflamed mucosa $(25,26)$. Concurrent with this enhanced inflammatory infiltrate is extensive mucosal injury, suggesting that the phagocytes play an active role in mediating some of the mucosal damage associated with this disease. It is known that the interaction of certain pro-inflammatory stimuli (eg, leukotriene B4, platelet activating factor) with specific receptors on the neutrophilic plasma membrane results in the production and release of large quantities of reactive oxygen metabolites such as superoxide $\left(\mathrm{O}_{2}^{-}\right)$and hydrogen peroxide $\left(\mathrm{H}_{2} \mathrm{O}_{2}\right)$. Neither superoxide nor hydrogen peroxide are particularly reactive; however, they will interact in the presence of certain transition metals such as iron $(\mathrm{Fe})$ to generate the highly reactive and cytotoxic hydroxyl radical $(\mathrm{OH} \cdot)$ :

$$
\begin{gathered}
\mathrm{O}_{2}^{-}+\mathrm{Fe}^{3+} \rightarrow \mathrm{O}_{2}+\mathrm{Fe}^{2+} \\
\mathrm{H}_{2} \mathrm{O}_{2}+\mathrm{Fe}^{2+} \rightarrow \mathrm{OH}^{-}+\mathrm{OH}^{-}+\mathrm{Fe}^{3+} \\
\text { sum: } \mathrm{O}_{2}^{-}+\mathrm{H}_{2} \mathrm{O}_{2} \rightarrow \mathrm{OH}^{-}+\mathrm{O}_{2}+\mathrm{OH} .
\end{gathered}
$$

The hydroxyl radical is one of the most potent oxidants produced in biological systems. It is capable of oxidizing and peroxidizing a wide variety of biomolecules such as protein, carbohydrate and lipid (27). Lipid peroxidation is a classical free radical reaction involving initiation, propagation and termination reactions:

Initiation: $\quad \mathrm{LH}+\mathrm{OH}^{\prime} \rightarrow \mathrm{L}^{\prime}+\mathrm{H}_{2} \mathrm{O}$

Propagation: $\mathrm{L} \cdot+\mathrm{O}_{2} \rightarrow \mathrm{LOO}$

$$
\mathrm{LOO}+\mathrm{LH} \rightarrow \mathrm{LOOH}+\mathrm{L}^{\prime}
$$

Termination: $\quad L^{\cdot}+L \cdot \rightarrow L-L$

$$
\mathrm{LOO}^{\circ}+\mathrm{L}^{\circ} \rightarrow \mathrm{LOOL}^{-}
$$

where $\mathrm{LH}, \mathrm{L}$; , LOO and $\mathrm{LOOH}$ represent polyunsaturated lipid, lipid alkyl

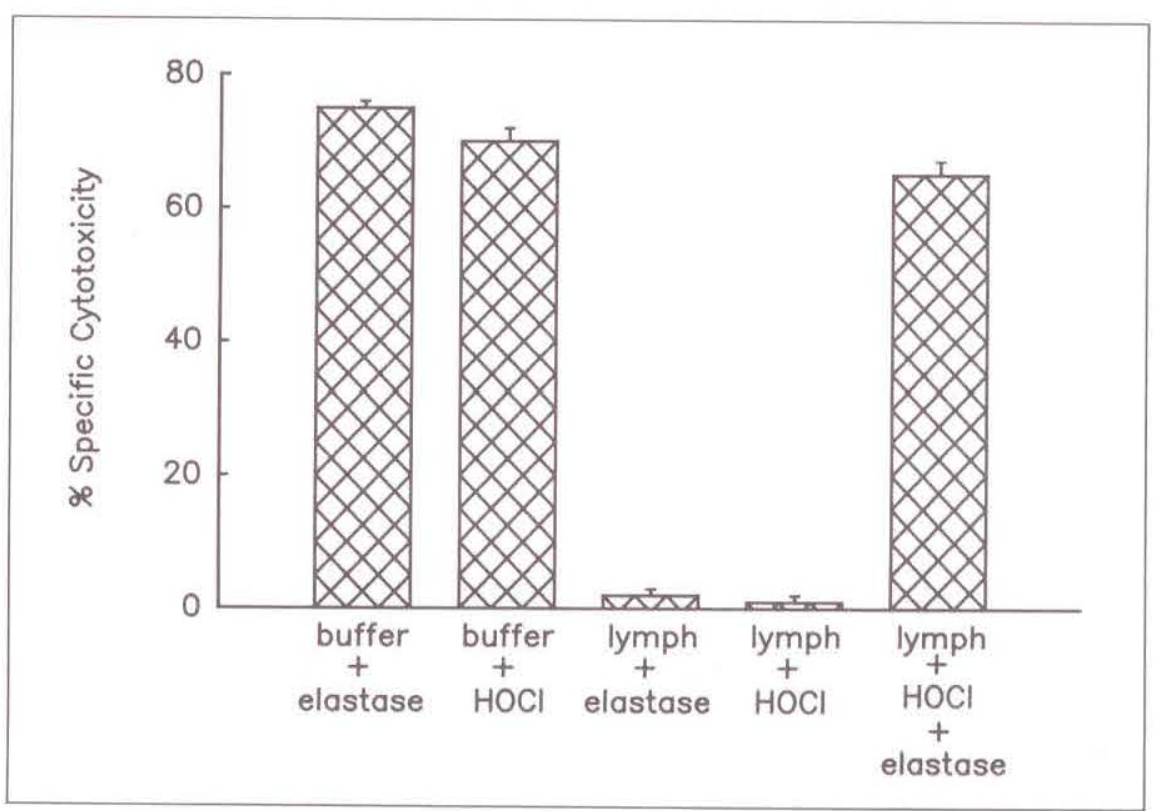

Figure 1) Antioxidant and antiprotease activity of intestinal lymph. Pig pancreatic elastase (25 $\mu \mathrm{g} / \mathrm{mL})$ and hypochlorous acid (HOCl) $(0.2 \mathrm{mM})$ were incubated with intestinal epithelial cells (IEC-18; $2 \times 10^{5}$ cells per well) in the absence or presence of rat intestinal lymph (50\%) for $4 \mathrm{~h}$ at $37^{\circ} \mathrm{C}$. For some experiments lymph was first exposed to hypochlorous acid $(0.2 \mathrm{mM})$ for $10 \mathrm{mins}$ at $37^{\circ} \mathrm{C}$ in the absence of intestinal epithelial cells. The solutions containing oxidized lymph and elastase were then added to the cells and incubated for an additional $4 \mathrm{~h}$ at $37^{\circ} \mathrm{C}$

radical, lipid hydroperoxyl radical and lipid hydroperoxide, respectively. Peroxidation of membrane lipids alters membrane fluidity and may dramatically affect lipid-protein interactions and enzymatic function (27). In addition to the hydroxyl radical, it is known that hydrogen peroxide will interact with hemoglobin to generate a hemoprotein-associated oxidant capable of initiating lipid peroxidation (28). These types of reactions may be important during active episodes of ulcerative colitis because bleeding into the mucosal interstitium will release hemoglobin in proximity to phagocytegenerated hydrogen peroxide (23). In addition to classic reactive oxygen metabolites, activated neutrophils and monocytes also secrete the hemoprotein myeloperoxidase into the extracellular medium where it catalyzes the oxidation of chloride ions by hydrogen peroxide to yield the highly reactive oxidizing and chlorinating agent hypochlorous acid ( $\mathrm{HOCl})$.

$$
\mathrm{H}_{2} \mathrm{O}_{2}+\mathrm{Cl}+\mathrm{H}^{+} \rightarrow \mathrm{H}_{2} \mathrm{O}+\mathrm{HOCl}
$$

Hypochlorous acid has been shown to degrade gastrointestinal mucin, enhance mucosal permeability and injure intestinal epithelial cells $(29,30)$. The authors have recently demonstrated that hypochlorous acid may mediate intestinal epithelial cell injury indirectly by inactivating certain protease inhibitors (alpha-1-protease inhibitor, alpha-2-macroglobulin) found in intestinal interstitial fluid (lymph). Figure 1 shows that intestinal lymph is extremely effective at inhibiting elastase- or hypochlorous acid-mediated cytotoxicity to intestinal epithelial cells in vitro. If, however, lymph is allowed to first interact with physiological levels of hypochlorous acid for 10 mins at $37^{\circ} \mathrm{C}$, it loses its ability to protect epithelial cells from a subsequent chal. lenge of elastase. The net result of these reactions in vivo would be uncontrolled, hypochlorous acid-dependent proteolysis.

Normally most cells and tissues are protected from the injurious effects of reactive oxygen metabolites by the action of certain antioxidant enzymes such as superoxide dismutase, catalase and glutathione peroxidase. However, the present authors have shown that the colonic mucosa contains relatively small levels of superoxide dismutase and catalase compared to other tissues such as the liver (31). Furthermore, 
TABLE 2

Antioxidant enzymes associated with intestinal lymph and epithelial cells

\begin{tabular}{lcccc}
\hline & $\begin{array}{c}\text { SOD } \\
\text { (units/mg) }\end{array}$ & $\begin{array}{c}\text { Catalase } \\
\text { (units } / \mathrm{mg})\end{array}$ & $\begin{array}{c}\mathrm{GSH} \\
(\mathrm{mU} / \mathrm{mg})\end{array}$ & $\begin{array}{c}\text { Protein SH } \\
\text { (nmol/mL) }\end{array}$ \\
\hline Lymph (feline) & 1.0 & 0.46 & 6.8 & 100 \\
IEC-18 & 26 & 12 & 6.1 & - \\
\hline
\end{tabular}

Data represent the means from duplicate determinations and are expressed per $\mathrm{mg}$ of protein. IEC-18 Rat intestinal epithelial cells; SOD Superoxide dismutase: GSH Gluthathione: SH Sulfhydryl

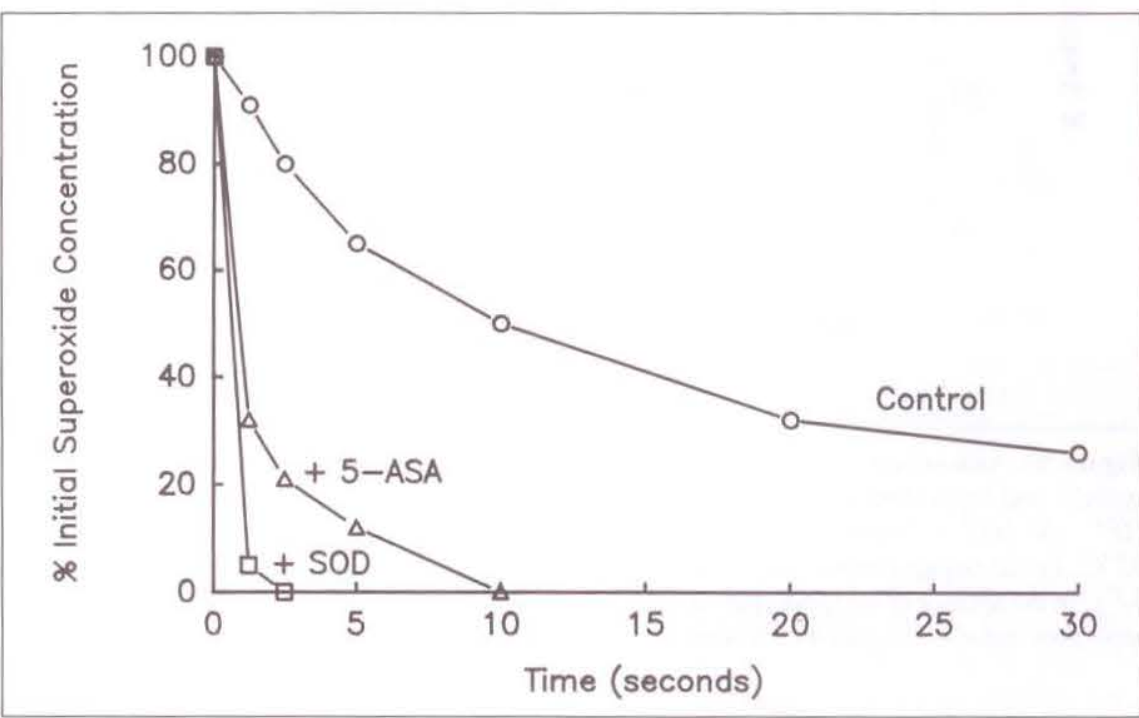

Figure 2) Decomposition of the superoxide anion radical mediated by 5-aminosalicylic acid (5-ASA) and superoxide dismutase (SOD). Decomposition of superoxide (potassium superoxide) was assessed by measurjing the decrease in absorbance at $250 \mathrm{~nm}$ ( $\lambda_{\max }$ for superoxide) at $\mathrm{pH} 9.0$ in the absence or presence of superoxide dismutase $(20 \mu \mathrm{g} / \mathrm{mL})$ or 5 -ASA $(0.25 \mathrm{mM})$

they have found that intestinal interstitial fluid (lymph) is deficient in these enzymes compared to enterocytes (Table 2). The potential for oxidantinduced mucosal injury may be further increased by the enhanced reactive oxygen metabolism determined for granulocytes obtained from patients with active inflammatory bowel disease (32-34). Using chemiluminescence as an indirect measure of active oxygen metabolism, Keshavarzian et al (35) have preliminary data to suggest that the inflamed colon produces significantly more active oxygen than does the healthy colon. Taken together, these data suggest that the inflamed colon may be subjected to considerable oxidative stress which would overwhelm the normally low levels of protective enzymes thus leading to mucosal injury. If this hypothesis is correct, then enhancing endogenous antioxidant levels may prove useful in protecting the mucosa during times of active inflammation. One drug that has potent antioxidant activity is 5-ASA.

\section{ANTIOXIDANT PROPERTIES OF 5-ASA}

It has been estimated that $4 \times 10^{6}$ human neutrophils will consume approximately $20 \mu \mathrm{M}$ oxygen/min when fully activated, and virtually all of this oxygen is converted to superoxide (36). Although superoxide per se is not very reactive or cytotoxic it will interact with iron to generate the toxic hydroxyl radical $(\mathrm{OH} \cdot)$. Thus, any compound that decomposes superoxide would attenuate superoxide-dependent formation of hydroxyl radicals. A recent report by Craven et al (18) demonstrated that 5-ASA has potent superoxide dismutase-like activity as measured by its ability to inhibit the reduction of cytochrome $c$ by xanthine oxidase-generated superoxide. Using a more direct assay for the decomposition of superoxide - ie, the direct spectrophotometric determination of the superoxide anion radical at $250 \mathrm{~nm}$ - it was found that 5-ASA interacts directly with superoxide, causing the rapid decomposition of this radical (Figure 2). The disappearance of superoxide may occur by two possible path. ways. One pathway would require the one electron reduction of superoxide by 5 -ASA in the presence of protons to yield hydrogen peroxide. The other way in which 5-ASA may decompose superoxide is by the one electron reduc. tion of 5-ASA by superoxide to yield oxygen. Because 5-ASA would acquire an odd electron by either pathway it would become, by definition, a free radical itself. The significance of these observations is currently under inves. tigation in the authors' laboratory. Phagocytic leukocytes also produce large amounts of hydrogen peroxide by the spontaneous or enzymatic (superoxide dismutase) dismutation of super. oxide:

$$
\mathrm{O}_{2}^{-}+\mathrm{O}_{2}^{-}+2 \mathrm{H}^{+} \rightarrow \mathrm{H}_{2} \mathrm{O}_{2}+\mathrm{O}_{2}
$$

The authors have found that 5-ASA reacts very sluggishly with hydrogen peroxide and thus is unlikely to participate in the decomposition of this oxidant in vivo. As already mentioned, superoxide and hydrogen peroxide will interact in the presence of iron to yield the highly reactive oxidant hydroxyl radical. This oxidant is capable of mediating the oxidative degradation of a variety of biomolecules, including lipid and carbohydrates. Work from several laboratories including the present authors' has demonstrated that 5 -ASA is very effective in scavenging the hydroxyl radical; however, the parent compound sulphasalazine and the metabolically inactive metabolites $n$-acetyl-5-ASA and sulfapyridine are also equally effective $(17,37)$. These data suggest that hydroxyl radical scavenging does not account for the therapeutic action of 5-ASA. In contrast with these studies, the authors have found that 5-ASA - but not sulphasalazine, n-acetyl-5-ASA sulfapyridine - is effective in inhibiting the lipid peroxidation $\left(\mathrm{IC}_{50} 8 \mu \mathrm{M}\right)$ initiated by organic peroxyl radicals generated from the thermal decomposition of 2,2' azobis (amidinopropane) 
dihydrochloride (A-N-N-A) (Figure 3):

$$
\begin{aligned}
& \mathrm{A}-\mathrm{N}-\mathrm{N}-\mathrm{A} \rightarrow \mathrm{A}^{\prime}+\mathrm{N}_{2}+\mathrm{A}^{\prime} \\
& \mathrm{A}+\mathrm{O}_{2} \rightarrow \mathrm{AOO} \\
& \mathrm{AOO}+\mathrm{LH} \rightarrow \mathrm{AOOH}+\mathrm{L} \\
& \mathrm{L} \cdot+\mathrm{O}_{2} \rightarrow \mathrm{LOO} \\
& \mathrm{LOO}+\mathrm{LH} \rightarrow \mathrm{LOOH}+\mathrm{L}^{\prime}
\end{aligned}
$$

where $\mathrm{A}, \mathrm{AOO}$ and $\mathrm{AOOH}$ represent the alkyl radical, peroxyl radical and hydroperoxide, respectively. Because lipid peroxidation is not initiated by the superoxide-dependent, ironcatalyzed formation of hydroxyl radical in this system, the inhibitory effect of 5-ASA is due solely to its ability to scavenge peroxyl free radicals. These data agree with and extend the findings of Ahnfelt-Ronne and Nielson (19), who demonstrated potent scavenging of a nitrogen-centred free radical by 5-ASA (IC50 $5 \mu \mathrm{M}$ ) but not by sulphasalazine or sulfapyridine. Another property of 5-ASA that may contribute to its antioxidant activity is its ability to chelate iron. Obviously, any compound capable of binding iron and rendering it poorly redox active would be very effective in inhibiting the formation of hydroxyl radicals. The authors have recently demonstrated that 5-ASA inhibits the iron-catalyzed, hydroxyl radical-mediated degradation of deoxyribose by chelating iron and preventing its interaction with superoxide and hydrogen peroxide (IC50 300 $\mu \mathrm{M})$ (37). n-Acetyl-5-ASA and sulphasalazine were only modestly effective, whereas sulfapyridine was inactive, suggesting a relatively selective effect by the therapeutically active metabolite.

Myeloperoxidase-catalyzed oxidation of chloride ions by hydrogen peroxide to yield hypochlorous acid represents another significant pathway of oxidant production in inflamed tissue. Recent work by von Ritter et al (38) demonstrated that 5-ASA, sulfapyridine, n-acetyl-5-ASA and sulphasalazine are all very effective at scavenging hypochlorous acid in vitro (IC50 25 to $30 \mu \mathrm{M})$. However, Aruoma and co-workers (17) have shown that 5.ASA was selective in its ability to protect alpha-1-protease inhibitor against inactivation by hypochlorous acid (IC50 $400 \mu \mathrm{M}$ ), suggesting that

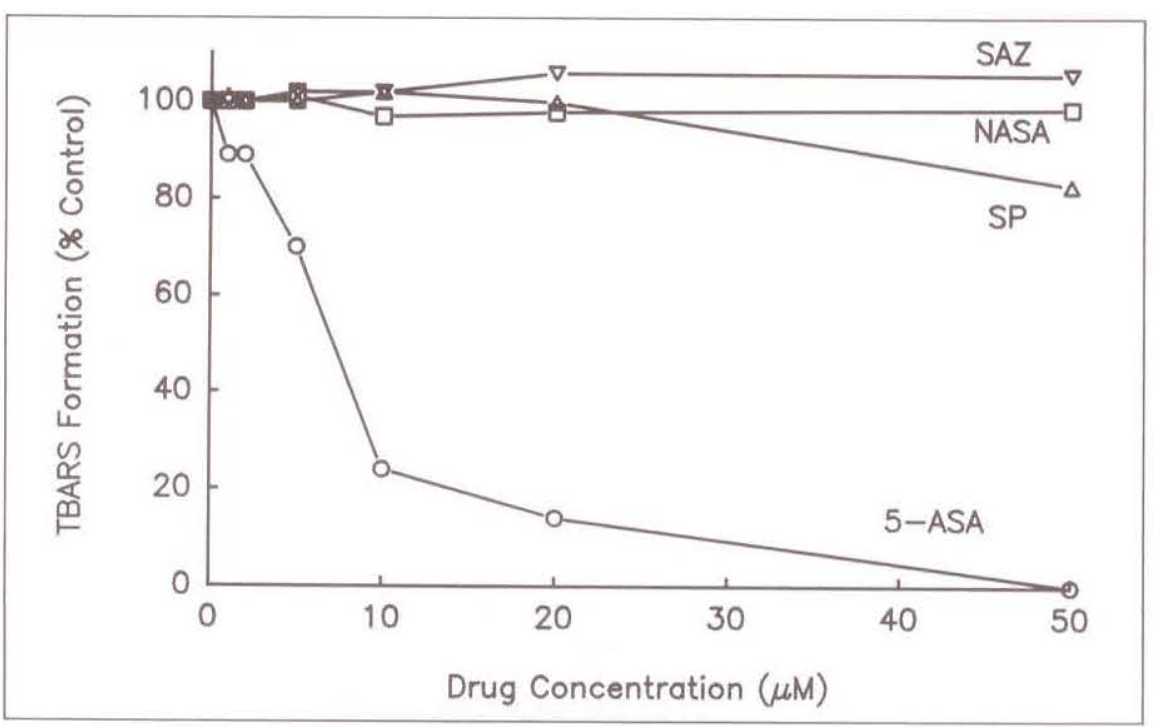

Figure 3) Effects of 5-aminosalicylic acid (5-ASA), sulphasalazine (SAZ), n-acetyl-5-ASA (NASA), and sulfapyridine (SP) on peroxyl radical-mediated lipid peroxidation. Lipid (80\% phosphotidyl choline) was incubated with the thermolabile free radical initiator 2,2'-azobis (amidinopropane) dihydrochloride for 30 mins at $37^{\circ} \mathrm{C}$ in the absence or presence of varying concentrations of sulphasalazine or its metabolites. Lipid peroxidation was determined by measuring the formation of thiobarbituric acid-reactive substances (TBARS)

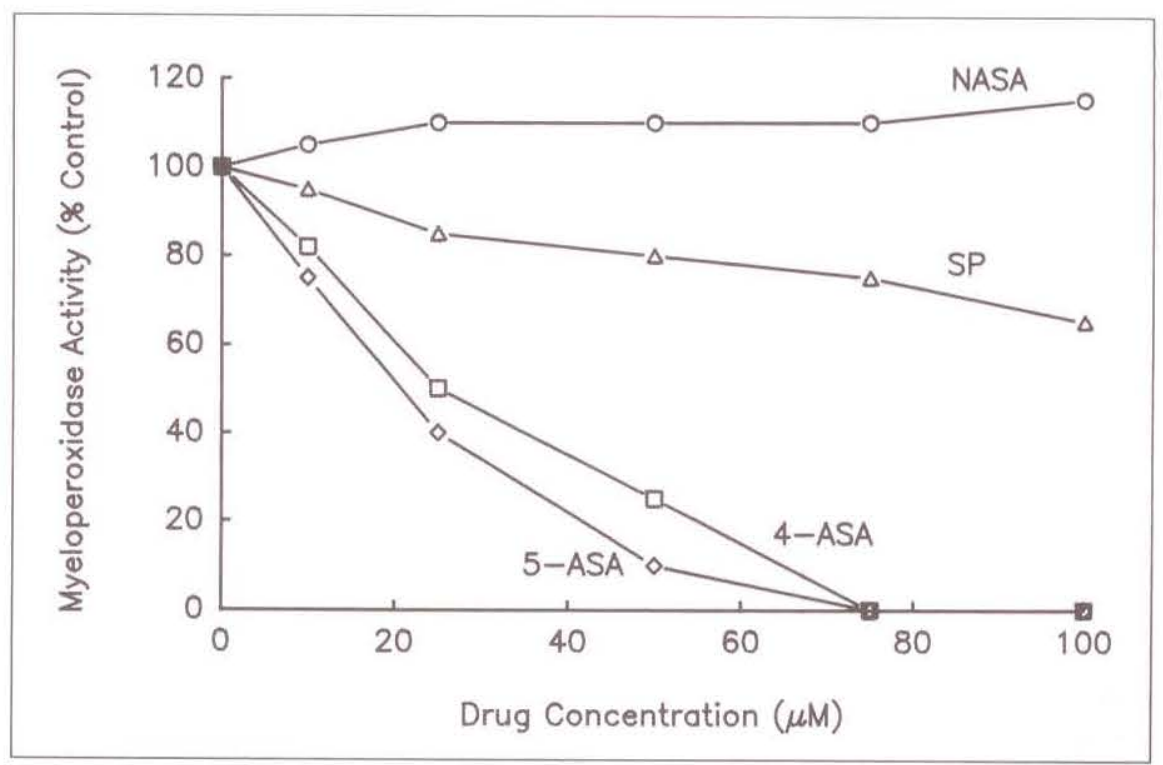

Figure 4) Effects of 5-aminosalicylic acid (5-ASA), 4-aminosalicylic acid (4-ASA), n-acetyl-5ASA (NASA) and sulfapyridine (SP) on myeloperoxidase activity. Human myeloperoxidase activity was assessed by measuring the hydrogen peroxide-dependent oxidation of $3,3^{\prime}, 5,5^{\prime}$. tetramethylbenzidine in the absence or presence of varying concentractions of sulphasalazine or its metabolites

some of the beneficial effects of 5-ASA may be due to its ability to interact selectively with and decompose hypochlorous acid in the presence of other biological compounds. The myeloperoxidase-catalyzed formation of hypochlorous acid requires interaction between hydrogen peroxide and the enzyme to form a potent hemoprotein- associated oxidant termed 'compound I'. This porphyrin cation radical is a potent oxidizing agent capable of oxidizing a wide variety of biological compounds in addition to chloride ions: $\mathrm{P}-\mathrm{Fe}^{3+}+\mathrm{H}_{2} \mathrm{O}_{2} \rightarrow \mathrm{P}^{++}-\mathrm{Fe}^{4+}=\mathrm{O}+\mathrm{OH}^{-}$

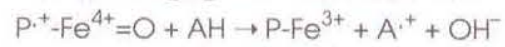

Where $\mathrm{P}-\mathrm{Fe}^{3+}, \mathrm{P}^{+}{ }^{+} \mathrm{Fe}^{4+}=\mathrm{O}, \mathrm{AH}$ and $\mathrm{A}^{+}$represent the hemoprotein, por- 


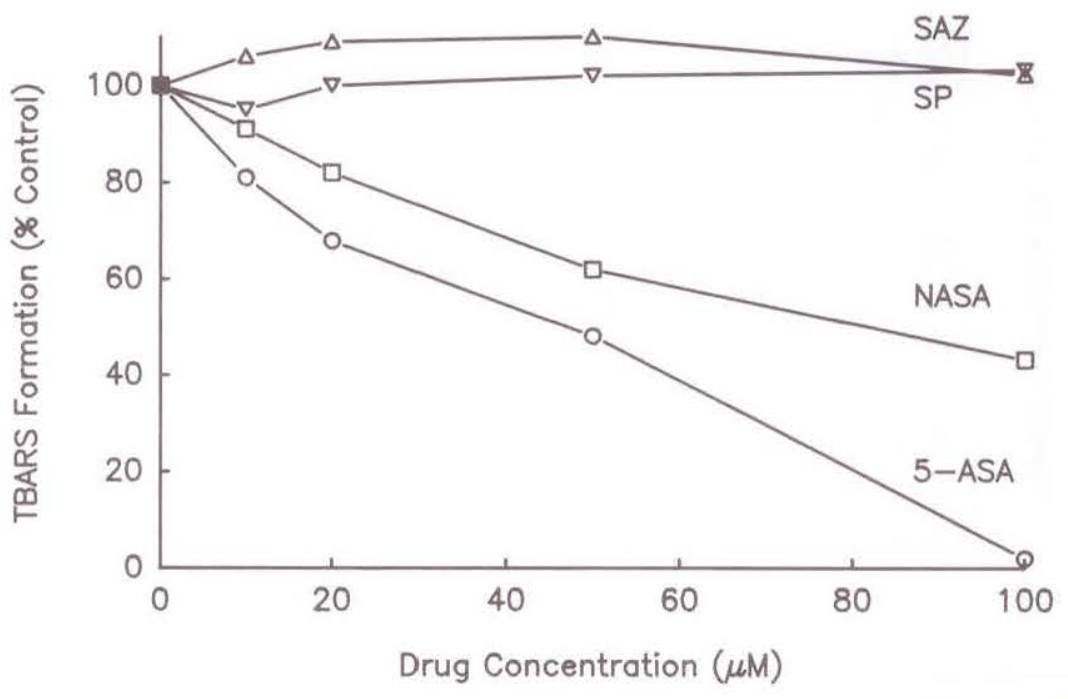

Figure 5) Effects of 5-aminosalicylic acid (5-ASA), n-acetyl-5-ASA (NASA), sulfapyridine (SP), and sulphasalazine (SAZ) on hemoglobin-catalyzed lipid peroxidation. Lipid was incubated in the absence or presence of varying amounts of sulphasalazine or its metabolites with hemoglobin $(0.02$ $\mathrm{mM})$ and hydrogen peroxide $(0.1 \mathrm{mM})$ for 20 mins at $37^{\circ} \mathrm{C}$. Lipid peroxidation was determined by measuring the formation of thiobarbituric acid-reactive substances (TBARS)

phyrin cation radical, substrate and oxidized substrate, respectively.

The present authors have found that 5-ASA and 4-aminosalicylic acid (4ASA) were much more effective in decomposing compound I of myeloperoxidase - and thus much more potent at inhibiting the activity of myeloperoxidase - than sulfapyridine or n-acetyl-5-ASA. IC50s of 20 and 25 $\mu \mathrm{M}$ were determined for 5 -ASA and 4-ASA, respectively (Figure 4). Apparently 5-ASA and 4-ASA act as alternative substrates for compound I, preferentially becoming oxidized instead of the substrate. It is quite possible that this is the reason why AhnfeltRonne et al (21) detected significant levels of oxidation products of 5-ASA in sulphasalazine-treated patients with active inflammatory bowel disease. It has also been suggested that the interstitial hemoglobin released during intestinal bleeding may mediate some of the mucosal injury by interacting with phagocyte-derived hydrogen peroxide to generate ferryl $\left(\mathrm{Fe}^{4+}\right)$ hemoglobin, a hemoprotein-associated free radical similar to myeloperoxidase compound I. Ferryl hemoglobin is a potent oxidant capable of initiating lipid peroxidation (28). The authors have found that 5 ASA - and to a lesser extent sul- phasalazine or sulfapyridine-selectively inhibit hemoglobin-catalyzed lipid peroxidation by acting as an alternative substrate for ferryl hemoglobin (IC50 $50 \mu \mathrm{M}$ ) (Figure 5). These types of reactions may help explain observations made by Hoult and Page (39), who demonstrated enhanced production of certain prostaglandins by colonic mucosa in the presence of relatively small concentrations of 5-ASA $(0.5$ $\mathrm{mM}$ ). It is known that prostaglandin synthetase contains two enzymatic activities, including cyclo-oxygenase and hemoprotein hydroperoxide peroxidase activities. During the enzymatic reaction there is progressive inhibition of the enzyme due to oxidative inactivation of the hemoprotein peroxidase. It is well known that certain antioxidants (eg, phenolic compounds) inhibit this inactivation process and prolong prostaglandin production. Apparently the lipid hydroperoxide generated by cyclo-oxygenase (prostaglandin $\mathrm{G}_{2}$ ) combines with the hemoprotein peroxidase to generate a compound Ilike oxidant. In the absence of an exogenous electron-donating substrate (antioxidant) the hemoprotein-localized free radical oxidizes certain amino acid residues proximal to the active site, which ultimately results in inac- tivation of the enzyme. It is intriguing to speculate that 5-ASA, by virtue of its antioxidant activity, may protect the mucosa by enhancing the formation of protective prostaglandins such as prostacyclin and/or prostaglandin E derivatives. Indeed recent reports suggest that certain prostaglandin $\mathrm{E}$ analogues are potent antiulcer compounds for the colon (40).

\section{SUMMARY AND CONCLUSIONS}

There is a growing body of ex. perimental data to suggest that the chronically inflamed intestine and/or colon may be subject to considerable oxidative stress. The most probable source of these oxidants is the phagocytic leukocytes since these cells are present in large numbers in the inflamed mucosa and are known to produce significant amounts of reactive oxygen species in response to certain inflammatory stimuli. Furthermore, the colonic mucosa contains relatively small amounts of the antioxidant enzymes superoxide dismutase and catalase. If reactive oxygen species play an important role in mediating mucosal injury in inflammatory bowel disease, then it should be possible to attenuate this injury by the use of antioxidants. Indeed, Emerit et al (41) have recently demonstrated, in a limited clinical study, that intramuscular administra. tion of superoxide dismutase protected the intestine from inflammatory tissue injury in patients with refractory Crohn's disease. In addition, a variety of antioxidant enzymes (superoxide dis. mutase, catalase) and scavengers have proven useful in attenuating the microvascular and mucosal injury associated with the acute intestinal in. flammation induced by ischemia (42). It may not be a coincidence that the anti-inflammatory metabolite 5-ASA is a potent antioxidant that possesses multiple mechanisms of action includ. ing nitrogen-, carbon- and oxygencentred free radical scavenging properties, and the ability to decom. pose hypochlorous acid and scavenge hemoprotein-associated oxidants. 5 . ASA has the additional property of being able to chelate iron. The reason 
that 5-ASA is so effective in vivo may be due to this multitude of antioxidant properties. This would also suggest that other, more potent antioxidants may prove beneficial in the treatment of inflammatory bowel disease.

\section{REFERENCES}

1. Riddell RH. Pathology of idiopathic inflammatory bowel disease. In: Kirsner JB, Shorter RG, eds. Inflammatory Bowel Disease. Philadelphia: Lea \& Febiger, 1988:329-50.

2. Azad-Khan AH, Piris J, Truelove SC. An experiment to determine the active therapeutic moiety of sulfasalazine. Lancet 1977; ii:892-5.

3. van Hees PAM, Bakker JH, van Tongeren JHM. Effect of sulfapyridine, 5-aminosalicylic acid, and placebo in patients with idiopathic proctitis: A study to determine the active therapeutic moiety of sulfasalazine. Gut 1980;21:632-5.

4. Klotz U, Maier K, Fischer C, Heinkel $K$. Therapeutic efficacy of sulfasalazine and its metabolites in patients with ulcerative colitis. N Engl J Med 1980;303:1499-502.

5. Hoult JRS, Moore PK. Effects of sulphasalazine and its metabolites on prostaglandin synthesis. Inactivation and actiogs on smooth muscle. $\mathrm{Br}$ ] Pharmacol 1980;68:719-30.

6. Hawkey C], Truelove SC. Inhibition of prostaglandin synthetase in human rectal mucosa. Gut 1983;24:213-7.

7. Stenson WF, Lobos E. Sulfasalazine inhibits the synthesis of chemotactic lipids by neutrophils. J Clin Invest 1982;69:494-7.

8. Allgayer $\mathrm{H}$, Stenson WF. A comparison of effects of sulfasalazine and its metabolites on the metabolism of endogenous vs exogenous arachidonic acid. Immunopharmacology 1988;15:39-46.

9. Molin L, Stendahl O. The effect of sulfasalazine and its active components on human polymorphonuclear leukocyte function in relation to ulcerative colitis. Acta Med Scand 1979;206:451-7.

10. Neal TM, Winterbourn CC, Vissers MCM. Inhibition of neutrophil degranulation and superoxide production by sulfasalazine: Comparison with 5-aminosalicylic acid, sulfapyridine and olsalazine. Biochem Pharmacol 1987;36:2765-8.

11. Miyachi Y, Yoshioka A, Imamura S, Niwa Y. Effect of sulphasalazine and its metabolites on the generation of reactive oxygen species. Gut 1987;28:190-5.

12. Carlin G, Djursater R, Smedegard G. Inhibitory effects of sulfasalazine and related compounds on superoxide production by human polymorphonuclear leukocytes. Pharmacol Toxicol 1989;65:121-7.

13. Stenson WF, Mehta J, Spilberg I. Sulfasalazine inhibition of binding of $n$-formyl-methionyl-leucyl-phenylalanine (FMLP) to its receptor on human neutrophils. Biochem Pharmacol 1984;33:407-12.

14. MacDermott RP, Schloemann SR, Bertovich M], Nash GS, Peters M, Stenson WF. Inhibition of antibody secretion by 5 -aminosalicylic acid. Gastroenterology 1989;96:442-8.

15. Carlin G, Djursater R, Smedegard G, Gerdin B. Effect of anti-inflammatory drugs on xanthine oxidase induced depolymerization of hyaluronic acid. Agents Actions 1985;16:377-84.

16. Betts WH, Whitehouse MW, Cleland LG, Vernon-Roberts B. In vitro antioxidant properties of potential biotransformation products of salicylate, sulphasalazine and amidopyrine. Free Radic Biol Med 1985;1:273-80.

17. Aruoma OI, Washil M, Halliwell B, Hoey BM, Butler J. The scavenging of oxidants by sulphasalazine and its metabolites: A possible contribution to their anti-inflammatory effects? Biochem Pharmacol 1987;36:3739-42.

18. Craven PA, Pfanstiel J, Saito R, DeRubertis FR. Actions of sulfasalazine and 5 -aminosalicylic acid as reactive oxygen scavengers in the suppression of bile acid-induced increases in colonic epithelial cell loss and proliferative activity. Gastroenterology 1987;92:1998-2008.

19. Ahnfelt-Ronne I, Nielsen $\mathrm{OH}$. The anti-inflammatory moiety of sulfasalazine, 5-aminosalicylic acid, is a radical scavenger. Agents Actions 1987;21:191-4.

20. Dull BJ, Salata K, Van Langenhove A, Goldman P. 5-aminosalicylate: Oxidation by activated leukocytes and protection of cultured cells from oxidative damage. Biochem Pharmacol 1987;36:2467-72.

21. Ahnfelt-Ronne I, Nielsen $\mathrm{OH}$, Christensen A, Langholz E, Reis P. Clinical evidence supporting the radical scavenger mechanism of 5-aminosalicylic acid. Gastroenterology 1990;98:1162-9.

22. Grisham MB. Antioxidant properties of 5-aminosalicylic acid toward neutrophil-derived oxidants. In: MacDermott RP, ed. Inflammatory Bowel Disease: Current Status and Future Approach. Amsterdam: Elsevier Science Publishers, 1988:261-6.

23. Grisham MB, Granger DN. Neutrophil-mediated mucosal injury: Role of reactive oxygen metabolites. Dig Dis Sci 1988;33:6-15.
24. Grisham MB, Granger DN. 5-aminosalicylic acid concentration in mucosal interstitium of cat small and large intestine. Dig Dis Sci 1989;34:573-8.

25. Sharon P, Stenson WF. Enhanced synthesis of leukotriene $\mathrm{B}_{4}$ by colonic mucosa in inflammatory bowel disease. Gastroenterology 1984;86:453-60.

26. Wengrower D, Eliakim R, Karmeli F, Razin E, Rachmilewitz D. Pathogenesis of ulcerative colitis: Enhanced colonic formation of inositol phosphatase (IP) and platelet activating factor. Gastroenterology 1987;92:1691.

27. Grisham MB, McCord JM. Chemistry and cytotoxicity of reactive oxygen metabolites. In: Tayler AE, Matalon S, Ward P, eds. Physiology of Oxygen Radicals. Bethesda: American Physiological Society, 1986:1-18.

28. Kanner J, Harel S. Initiation of membranal lipid peroxidation by activated metmyoglobin and methemoglobin. Arch Biochem Biophys 1985;237:314-21.

29. Roberts GP, Gibbons RA. The action of neutral hypochlorite on epithelial mucopolysaccharides. Biochem J 1966;98:426-37.

30. Grisham MB, Gaginella TS, von Ritter C, Tamai H, Be RM, Granger DN. The effects of neutrophil-derived oxidants on intestinal permeability, electrolyte transport and epithelial cell viability. Inflammation 1990;14:531-42.

31. Grisham MB, MacDermott RP, Deitch EA. Antioxidant enzyme activities in the human colon. Inflammation. (In press)

32. Anton PA, Targan SR, Shanahan F. F-Met-Leu-Phe induced chemiluminescence and binding in neutrophils from patients with inflammatory bowel disease. In: MacDermott RP, ed. Inflammatory Bowel Disease: Current Concepts and Future Approach. Amsterdam: Excerpta Medica, 1988:285-90.

33. Kitahora T, Suzuki K, Asakura H, et al. Active oxygen species generated by monocytes and polymorphonuclear leukocytes in Crohn's disease. Dig Dis Sci 1988;33:951-5.

34. Shirabata Y, Aoki S, Takada S, et al. Oxygen derived free radical generating capacity of PMN in patients with ulcerative colitis. Digestion 1989;44:163-71.

35. Keshavarzian A, Kanofsky JR, Ibrahim $\mathrm{CM}$, Doria MI. Excessive generation of reactive oxygen metabolites by colonic mucosa in experimental colitis: Analysis by using chemiluminescence probe. FASEB J 1990;4:761. (Abst)

36. Tauber AI, Babior BM. Neutrophil oxygen reduction: The enzymes and the products. Free Radic Biol Med 1985;1:265-307.

37. Grisham MB. Effect of 5-amino- 
salicylic acid on ferrous sulfatemediated damage to deoxyribose. Biochem Pharmacol 1990;39:2060-3.

38. von Ritter C, Grisham MB, Granger DN. Sulfasalazine metabolites and dapsone attenuate formyl-methionyl. leucyl-phenylalanine-induced mucosal injury in rat ileum. Gastroenterology 1989;96:811-6.
39. Hoult JRS, Page H. 5-aminosalicylic acid, a co-factor for colonic prostacyclin synthesis? Lancet 1981;ii: 255.

40. Fedorak RN, Empey LR, MacArthur C, Jewell LD. Misoprostol provides a colonic mucosal protective effect during acetic acid-induced colitis in rats. Gastroenterology 1990;98:615. 25.
41. Emerit J, Pelletier S, Tosoni-Verlignue D, Mollet M. Phase II trial of copper zinc superoxide dismutase (CuZnSOD) in treatment of Crohn's disease. Free Radic Biol Med 1989;7:145-9.

42. Granger DN. Role of xanthine oxidase and granulocytes in ischemia-reperfusion injury. Am J Physiol 1988;255:1269-75. 


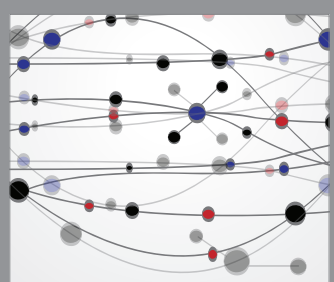

The Scientific World Journal
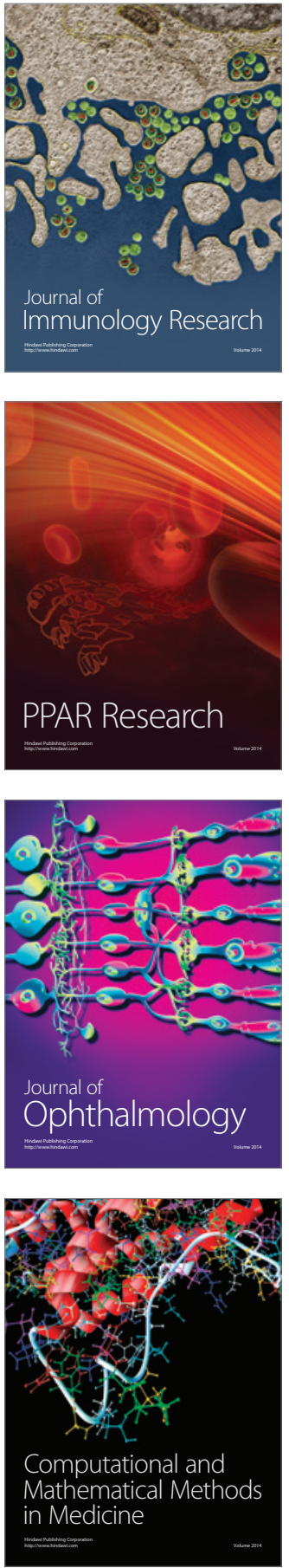

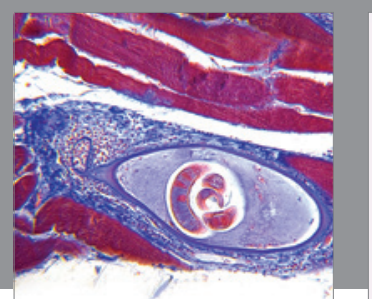

Gastroenterology Research and Practice

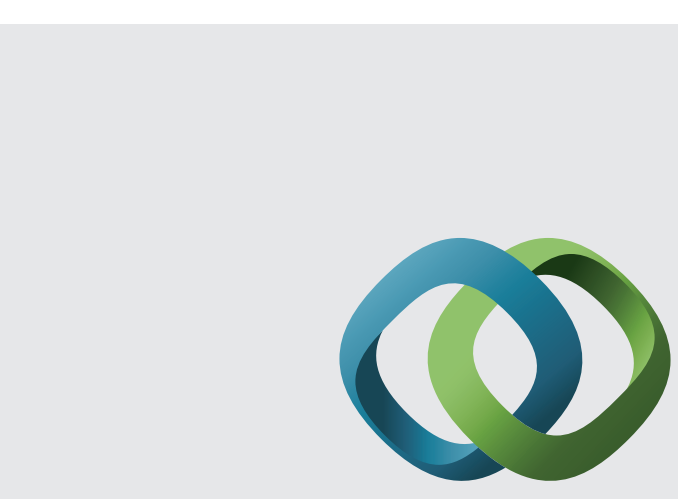

\section{Hindawi}

Submit your manuscripts at

http://www.hindawi.com
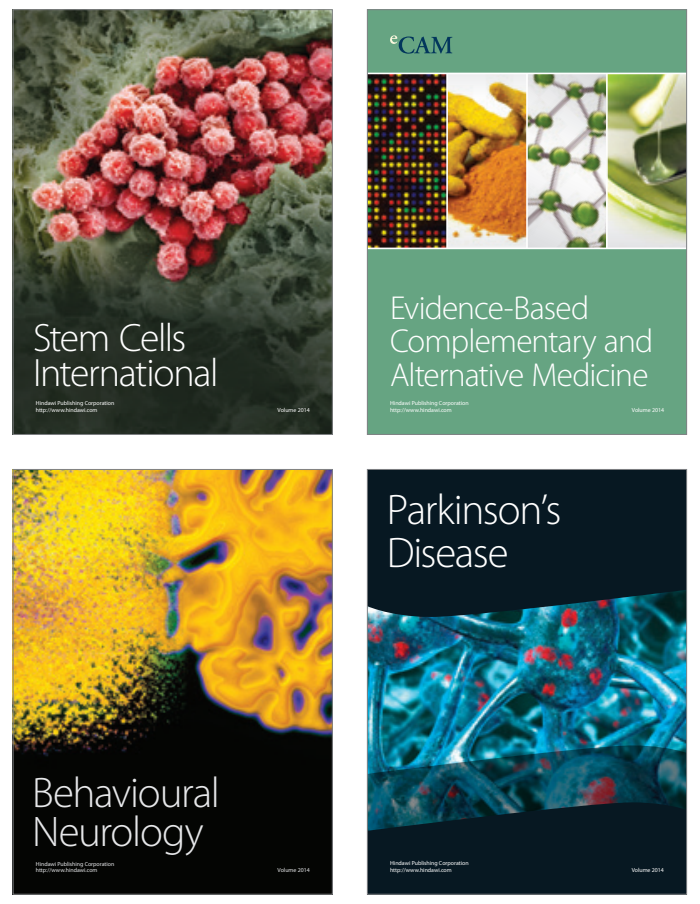
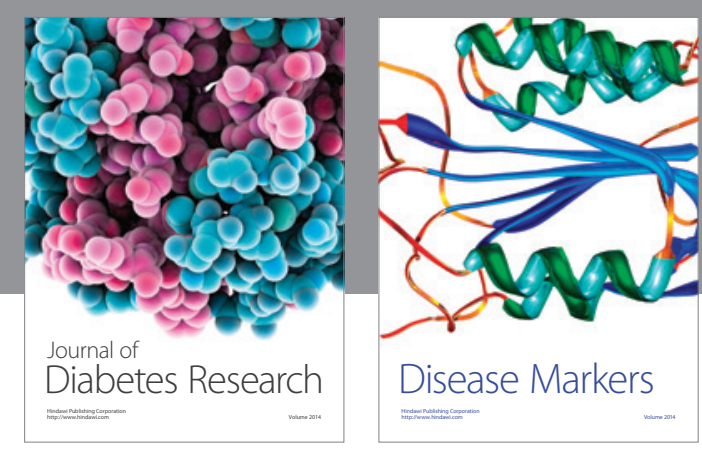

Disease Markers
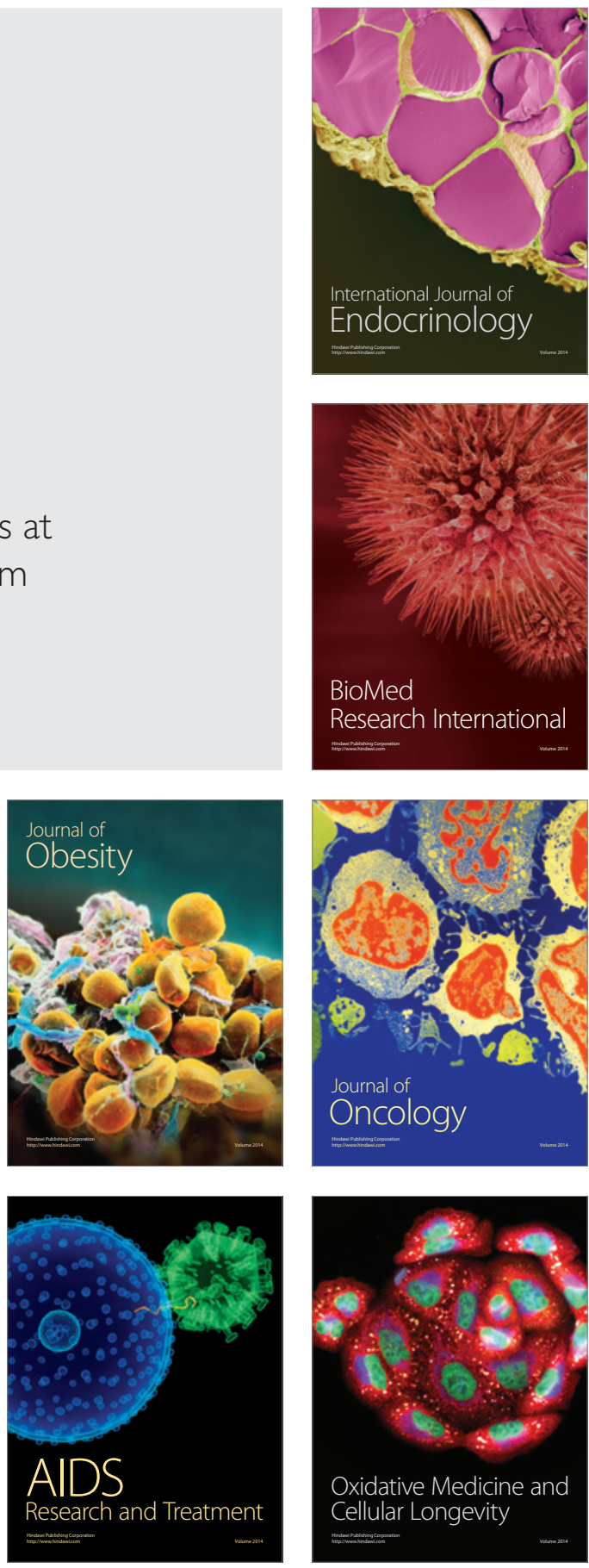